\title{
Geology and Diamonds: The Star and Orion South Kimberlites, Fort à la Corne, Canada
}

\author{
S. Harvey ${ }^{1}$, M. Shimell ${ }^{1}$, L. Fourie ${ }^{1}$, P. Du Plessis ${ }^{1}$, G. Read ${ }^{1}$, and B. Kjarsgaard ${ }^{2}$ \\ ${ }^{1}$ Shore Gold Inc., Saskatoon, Canada, ${ }^{2}$ Geological Survey of Canada, Ottawa, Canada
}

\begin{abstract}
Introduction
The Fort à la Corne (FalC) Orion South and Star kimberlites form kimberlite complexes that represent some of the largest kimberlite deposits in the world (Scott-Smith et al., 1998). The kimberlites are not mono-eruptive, carroted-shaped bodies but multieruptive volcanicalastic kimberlite complexes with variably shaped volcanic edifices and related shallow craters fed by narrow conduits. Evaluation of these large tonnage, low grade kimberlite complexes has required a methodic and multi-branched exploration strategy.
\end{abstract}

\section{Geological Setting}

The FalC kimberlite field is situated in east-central Saskatchewan, Canada $60 \mathrm{~km}$ east of the city of Prince Albert (Fig. 1). There are seventy-five kimberlites in the FalC area the bulk of which, 58, are in the main FalC trend surrounded by several satellite clusters. Importantly, $75 \%$ of the kimberlites have proven to be diamond bearing and close to $50 \%$ have been proven to be macrodiamond bearing. The FalC Joint Venture (60\% Shore Gold Inc. (Shore) and 40\% Newmont Mining Corporation of Canada Limited) currently control 65 of the kimberlites within the main cluster and the Snowden cluster. Shore has claims covering the Star and \#137 kimberlites along with the Weirdale, Foxford and Birchbark kimberlites.

The FalC kimberlites are approximately 95-105 Ma in age and erupted contemporaneously with Cretaceous Mannville and Colorado Group sedimentation. The mid-Cretaceous Colorado Group is between 70 and $90 \mathrm{~m}$ thick while the underlying Mannville Group is 100 to $165 \mathrm{~m}$ thick. Below the Cretaceous sediments are Paleozoic carbonates with lesser mixed silicilastics which have thicknesses of $400 \mathrm{~m}$. These Phanerozoic deposits were unconformably deposited on Paleoproterozoic rocks of the Trans-Hudsn Orogen, which structurally lie above rocks of the Archaean Sask Craton (Lucas et al., 1994).

\section{Exploration History}

The discovery of the FalC kimberlite field began by the discovery of kimberlite in the Sturgeon Lake area $30 \mathrm{~km}$ northwest of Prince Albert and $90 \mathrm{~km}$ west of FalC (Fig. 1). In late-July 1988 Uranerz Exploration and Mining Ltd. examined Geological Survey of Canada (GSC) $800 \mathrm{~m}$ line-spaced regional aeromagnetic maps and concluded that the

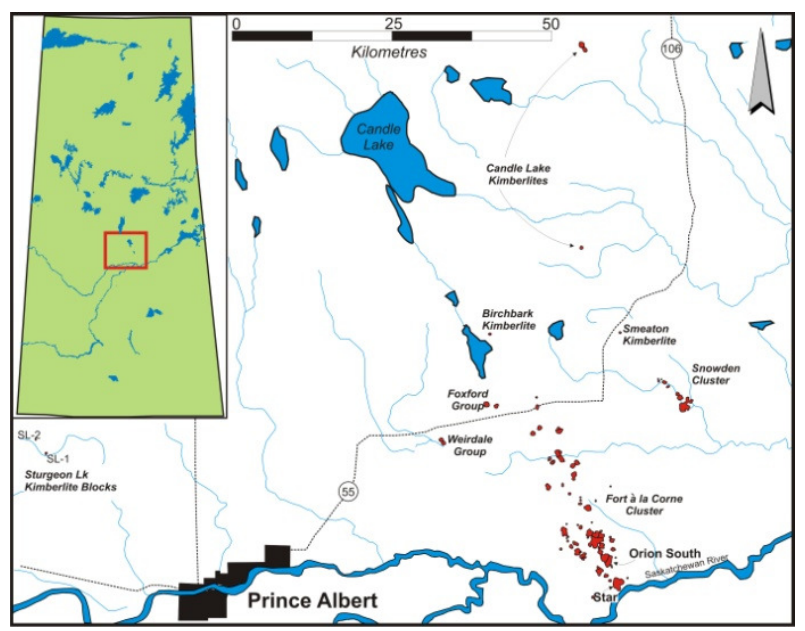

Fig. 1 Regional map of Fort à la Corne Kimberlite Field (kimberlites shown in red).

most prospective anomalies occurred not in the Sturgeon Lake area but in the FalC forest area.

A more detailed aeromagnetic survey over the FalC area in 1989-1990 delineated 70 anomalies, which were modeled to occur between 80 and $120 \mathrm{~m}$ below the surface. Ground magnetic surveys verified and characterized the anomalies and in July of 1989 the first in situ kimberlite in the FalC area was drill intersected.

Throughout much of the 1990s work emphasized on characterization of all the kimberlites on the FalC JV properties. This included geophysics, drilling, heavy mineral and diamond analysis. With such a large number of targets, prioritization was challenging with at least one hole being drilled in every anomally. Through the mid- to late-1990s work generally focused on drilling targets while geophysical characterization became secondary. As drilling progressed the more promising targets garnered more attention via large diameter drilling and further geophysical examination.

Recent work has emphasized macrodiamond recovery via small to large tonnage bulk and mini-bulk samples from higher priority targets including the Star Kimberlite and the Orion cluster on the joint venture property. These programs have relied on underground bulk sampling along with 24-, 36-, and 48-inch reverse circulation air-lift assist drill holes. Since 2004 work has been focused on the Star and the Orion cluster of 
kimberlites with particular focus on Star and Orion South at the southern limit of the main FalC trend.

\section{Recent Exploration Strategy}

In order to gain a significant understanding of the high priority kimberlite targets a three branched strategy was developed. Firstly, core drilling was completed on grid patterns to gain an understanding of the threedimensional architecture of the kimberlite complexes and its internal units. Augmenting the core drilling were downhole geophysical logging, detailed quantitative core logging, and whole-rock geochemical analyses. Secondly, underground bulk sampling provides appreciable carats for accurate estimate of diamond grade and value. Thirdly, large-diameter reverse circulation mini-bulk sampling provides an understanding of the diamond grade across the breadth of the kimberlite.Underground and LDD sampling is completed on Star and in progress at Orion South.

\section{i) Core Drilling}

Since 1992 and 1996 on Orion South and Star, respectively, several drill programs have been completed on the kimberlite complexes. Up to June 2008, 137 (33,773m of drilling) and 197 (45,624m of drilling) surface exploration holes were completed on Orion South and Star on $100 \mathrm{~m}$ grid spacing on the thicker portions of the complexes and $200 \mathrm{~m}$ spacing on the thinner periphery (Fig. 2). In addition, 212 BQsized underground core holes were completed on the Star kimberlite totaling $18,863 \mathrm{~m}$. In general, drilling has revealed that the kimberlites are comprised of multiple eruptive units (or phases) each of which is texturally, mineralogically, physically and chemically distinct. More importantly, these units have different diamond grades and values. Within the kimberlite complexes the units have cross-cutting relationships near conduits, but are stacked vertically within the volcanic edifice and crater/extra-crater deposits. Several conduits, feeding different units, have been identified both on the Orion South and Star.

Kimberlite volcaniclastics and Cretaceous sediment were deposited contemporaneously from ca 105-94 Ma. During Cantuar (Mannville Group) deposition, thought to be a time of continental fluvial-deltaic deposition (Zonneveld et al., 2004), kimberlite was deposited and reworked. Drilling has revealed that the Cantuar-aged kimberlite deposits are generally thin ( $<30 \mathrm{~m}$ thick) sheets occurring at multiple (up to 4 ) horizons within the Cantuar sedimentary pile. The bulk of the kimberlite deposits are confined within the marginal-marine to marine sedimentary strata (Zonneveld et al., 2004) of the Upper Manville (Pense Formation) and the Lower Colorado (upper Joli Fou Formation) groups. On both Star and Orion South these kimberlite deposits are associated with the main crater excavation and crater fill. Proximal to the conduits and in close proximity to the base of the Mannville Group sandstone (Scott-Smith et al., 1998) the conduits flare at a steep angle giving way to shallow angles near the margin of the craters (Fig. 3).

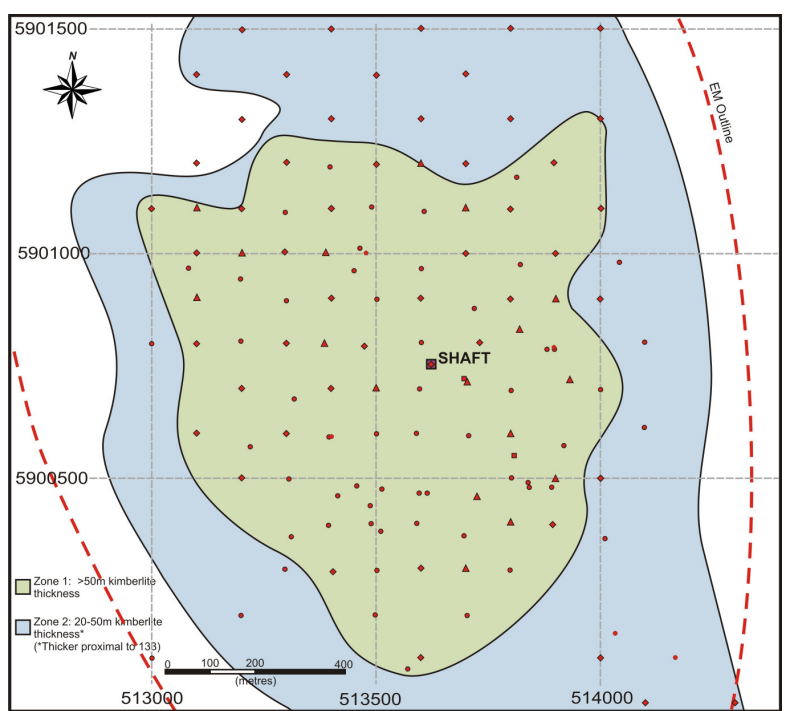

Fig. 2 Completed core hole (holes in red) drilling grid on the FalC JV Orion South kimberlite complex.

There are generally three main types of volcaniclastic kimberlite that form the bulk of the Star and Orion South bodies: 1) At Orion South (and not present at Star) is a fine- to medium-grained, matrix-rich, poorly sorted, massive to weakly bedded volcaniclastic kimberlite that forms a positive relief tephra cone (Pense age-equivalent). 2) At both Star and Orion

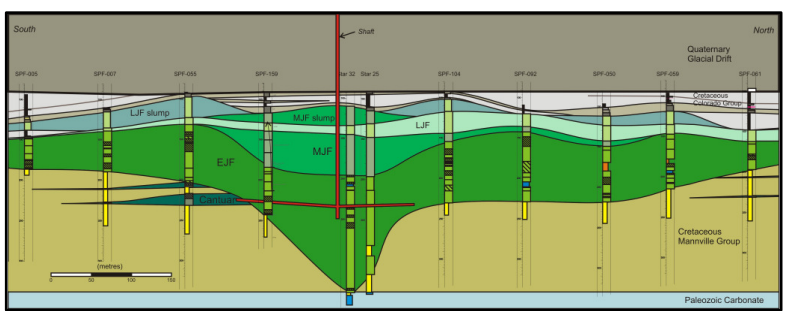

Fig. 3 Cross-section across the Star Kimberlite illustrating the host Cretaceous sedimentary rocks and the relationship with distinct kimberlite eruptive units (shades of green) and reworked equivalents.

South there is a variably fine- to coarse-grained, olivine-clast-rich, moderately to well sorted, bedded volcaniclastic kimberlite of early Joli Fou age (EJF). These deposits consist of multiple fining-up beds with medium- to very coarse-grained bases and finergrained tops. Commonly the bases are xenolith-rich kimberlite breccia. These deposits form the bulk of the vent/crater fill, tephra ring and distal (extra-crater) deposits at Star. At Orion South two separate EJF vents cross-cut the earlier Pense phase with vent fill, proximal and distal EJF volcaniclastic deposits overlying the Pense tephra cone. EJF volcaniclastic rocks are fine ash-sized component depleted, resulting in clast-supported, olivine-rich kimberlite deposits. This type of kimberlite is dominant on both Star and Orion South. 3.) A very fine- to fine-grained, well sorted, massive to weakly bedded volcaniclastic kimberlite of late Joli Fou equivalent age (LJF). At Orion South the LJF matrix consists of closely-packed, sub-1mm olivine grains, while at Star the matrix appears to be very fine-grained ash. These units have spatially restricted, narrow feeder conduits that cut through the pre-existing kimberlite deposits and have 
thick proximal deposits that quickly thin distally. Epiclastic deposits form minor volumes of the upper periphery of the complexes and vary from olivine-rich kimberlitic sandstones through to weakly kimberlitic siltstones.

Core data has led to the three-dimensional interpretation of the architecture of the kimberlite complexes. The upper surface of the main olivine-rich EJF VK at Star is shown in figure 4. There are three main areas: a central low, a circular high surrounding the central low, and an outer zone at moderate to low level. The thickest deposits are below the central low. These areas are correlative with: a central vent/crater, a positive relief tephra ring, and an extra-crater (tephraring distal) zone.

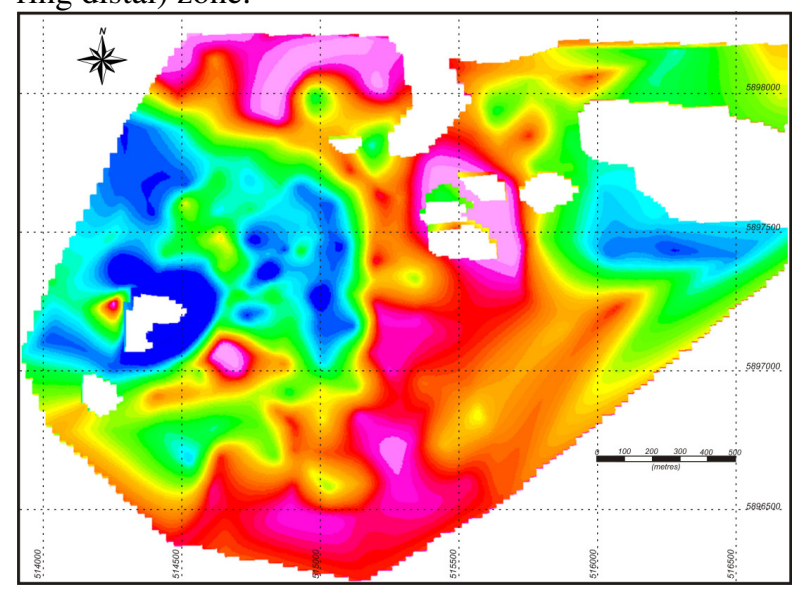

Fig. 4 Topographic elevation map (lows are blue; highs are magenta) of the main olivine-rich kimberlite unit (Early Joli Fou) on the Star Kimberlite.

3-D solids modeling of 400 core holes returns a total of 276 million tonnes of kimberlite in situ on the Star kimberlite complex; the bulk of that being represented by the EJF olivine-rich bedded kimberlite. Similarly, 3D modeling of 137 core holes on Orion South has revealed an estimated 360 to 400 million tonnes of kimberlite in situ with 176-196 million tonnes of EJF olivine-rich bedded kimberlite.

\section{ii) Bulk Sampling}

Star Kimberlite: Between 2004 and 2007 three phases of underground exploration were completed at Star recovering a total of 71,955.75 metric dry tonnes of kimberlite. Processing recovered 10,842.65 carats with the largest stone weighing 49.50 carats. The volumetrically largest unit, the olivine-rich (Early Joli Fou) kimberlite, returned a grade of $18 \mathrm{cpht}$.

In mid-2007, WWW International Diamond Consultants Ltd. carried out a final valuation on a 10,309.07 carat parcel. In late-2007 Shore announced WWW applied modeled values for the parcel ranging between US $\$ 97$ and US\$300 per carat for the different kimberlite lithologies and returned an average value of US\$170 per carat for the entire data set.

Orion South: In late 2007 the Orion South shaft sinking intersected kimberlite at $102.6 \mathrm{~m}$ below surface and by March, 2008 the first bulk sample shaft results were released. Samples recovered from $101.9 \mathrm{~m}$ to $148.6 \mathrm{~m}$ depth were recovered returning a total dry tonnage of 2,144.86 tonnes and a total of 363.08 carats with the largest stone being a 15.88 carat white stone. Bulk sampling is planned to continue through 2008 with completion in late 2009.

\section{iii) Large Diameter Drilling (LDD)}

In order to extrapolate the underground grades across the the kimberlite bodies, LD drilling has been completed on Star and is in progress on Orion South. Between September 2005 and December 2007, 88 LDD (48-inch diameter) holes were completed on the Star kimberlite. A total of $18,683 \mathrm{~m}$ of kimberlitic material was sampled for diamond recovery. A grid spacing of $100 \mathrm{~m}$ was the target with the bulk of the drilling being concentrated in the thicker portions of the kimberlite coincident with the vent and crater fill area. On Orion South there has been a longer history of LD drilling where between 2000 and 2004 twenty-four LDD holes were completed returning $3,263 \mathrm{~m}$ of kimberlite for diamond recovery. These holes were 24 and 36-inch diameter. In spring 2007, four 48-inch LDD holes were drilled before the implementation of the recent systematic LD drilling exploration program was initiated. This program, initiated in early 2008, has 27 LD (48-inch) holes being drilled on 140m spacing with a second phase of drilling to a $100 \mathrm{~m}$ grid planned if necessary.

\section{Summary}

The three pronged exploration strategy taking place on Star and Orion South has lead to a strong geological basis for understanding these two kimberlite complexes with an important recognition of different kimberlite units, each with different diamond grades and values. The recognition of these units has allowed Shore and the FalC JV to prioritize the largest and most promising units in each of Orion South and Star. With this prioritization, systematic underground bulk sampling and LD mini-bulk sampling has been completed on Star and is in progress on Orion South. This will enable an accurate estimate of resource potential on these two targets.

\section{References}

Lucas, S.B., White, D., Hajnal, Z., Lewry, J., Green, A., Ashton, K., Schledewitz, D.,Stauffer, M., Norman, A., Williams, P.F., and Spence, G., 1994. Three-dimensional collisional structure of the Trans-Hudson Orogen, Canada; Tectonophysics, v232, p161-178.

Scott-Smith, B.H., Orr, R.G., Robertshaw, P., Avery, R.A., 1998. Geology of the Fort à la Corne Kimberlites,

Saskatchewan. 7th International Kimberlite Conference, Cape Town, South Africa, Extended Abstracts vol., 772-774.

Zonneveld, J-P., Kjarsgaard, B.A., Harvey, Heaman, L.M., McNeil, D.H., Marcia, K.Y., 2004. Sedimentologic and stratigraphic constraints on emplacement of the Star Kimberlite, east-Central Saskatchewan. Lithos, v76, p115138. 